\title{
Association of household secondhand smoke exposure and mortality risk in patients with heart failure
}

\author{
Xin $\mathrm{He}^{1,2 \dagger}$, Jingjing Zhao ${ }^{1,2 \dagger}$, Jiangui He ${ }^{1,2}$, Yugang Dong ${ }^{1,2^{*}}$ and Chen $\mathrm{Liu}^{1,2^{*}}$ (D)
}

\begin{abstract}
Background: Secondhand smoke (SHS) exposure is a well-established cardiovascular risk factor, yet association between SHS and prognosis of heart failure remains uncertain.

Method: Data were obtained from the US National Health and Nutrition Examination Surveys III from 1988 to 1994. Currently nonsmoking adults with a self-reported history of heart failure were included. Household SHS exposure was assessed by questionnaire. Participants were followed up through December 31, 2011. Cox proportionalhazards models were used to assess the association of household SHS exposure and mortality risk. Potential confounding factors were adjusted.

Results: Of 572 currently nonsmoking patients with heart failure, 88 were exposed to household SHS while 484 were not. There were totally 475 deaths during follow-up. In univariate analysis, household SHS was not associated with mortality risk (hazard ratio [HR]: 0.98, 95\% confidence interval [CI]: 0.76-1.26, $p=0.864$ ). However, after adjustment for demographic variables, socioeconomic variables and medication, heart failure patients in exposed group had a $43 \%$ increase of mortality risk compared with those in unexposed group (HR: 1.43, 95\% Cl: 1.10-1.86, $p=0.007)$. Analysis with further adjustment for general health status and comorbidities yielded similar result (HR: 1.47, 95\% Cl: 1.13-1.92, $p=0.005)$.
\end{abstract}

Conclusion: Household SHS exposure was associated with increased mortality risk in heart failure patients.

Keywords: Heart failure, Secondhand smoke, Mortality

\section{Background}

Heart failure is a complex clinical syndrome with diverse etiology. It affects $1-2 \%$ adults and $\geq 10 \%$ elderly population in developed countries [1-4]. The lifetime risk of developing heart failure is so high as $20 \%$ for those older than 40 [5]. Prognosis of heart failure remains poor. Absolute mortality rate within 5 years is approximately $50 \%$ $[6,7]$. Smoking is associated with higher risk of death in patients with left ventricular dysfunction, and therefore, smoking cessation is recommended in patients with heart failure [8-10].

Secondhand smoke (SHS) is another modifiable risk factor for cardiovascular diseases. Studies have shown

* Correspondence: dongxg@mail.sysu.edu.cn; liuch75@mail.sysu.edu.cn

${ }^{+}$Xin He and Jingjing Zhao contributed equally to this work.

${ }^{1}$ Department of Cardiology, The First Affiliated Hospital of Sun Yat-sen

University, Guangzhou, China

Full list of author information is available at the end of the article that SHS also had significant adverse effect on cardiovascular system [11]. Although a previous study using cross-sectional data showed that SHS exposure was associated with lower quality of life in patients with heart failure [12], the effect of SHS exposure on prognosis of heart failure remains uncertain.

Thus, we hypothesized that heart failure patients exposed to household SHS would have higher risk of allcause mortality. We investigated the association of household SHS exposure and mortality risk using data of the US National Health and Nutrition Examination Surveys (NHANES) III.

\section{Methods \\ Participants}

NHANES III is cross-sectional survey in a nationwide probability sample of non-institutionalized civilian 
resident population in the United States. It is designed to assess the health and nutritional status of adults and children in the United States. From 1988 to 1994, 33,994 sample participants were interviewed and 30,818 participants were examined. Detailed descriptions of plan and operation of NHANES III is available on the website of National Center for Health Statistics [13]. The study was approved by the National Center for Health Statistics Research Ethics Review Board, and a signed informed consent form was obtained from every participant. Our study included currently nonsmoking adults ( $\geq 18$ years) with a self-reported history of heart failure from survey participation. Participants with a history of non-skin cancer were excluded because of poor prognosis. There were totally 19,592 adults in NHANES III. Among them, 18,810 denied a history of heart failure, and 28 had no idea about their heart failure history. There were 757 participants with a history of heart failure in NHANES III. Among them, 126 current smokers and 59 participants with a history of non-skin cancer were excluded. Finally, 572 heart failure patients were included in the analysis.

\section{Household SHS exposure}

Data on household SHS exposure were obtained from the Family Characteristics section of the interview. The specific question was "Does anyone who lives here smoke cigarettes?" If the answer was yes, the participant was considered to be exposed to household SHS.

\section{Outcome}

Data on mortality status of included participants were obtained from the 2011 Public-Use Mortality Linked File. The file provided mortality follow-up data from the date of survey participation through December 31, 2011. Identifier data were matched to the National Death Index using a probabilistic matching algorithm. A detailed description of the linkage methodology has been published [14].

\section{Statistical analysis}

The primary analytic goal was to assess the association of household SHS exposure and mortality risk in patients with heart failure.

Continuous variables were expressed as mean $\pm \mathrm{SD}$, and categorical variables were expressed as percentage. The differences between groups were tested by $t$ test and Pearson's chi-squared test, respectively.

We calculated unadjusted rates of death per personyear. Kaplan-Meier survival curves and log-rank test were used to evaluate the mortality risk of SHS exposed and unexposed group. We used univariate Cox proportional-hazards models to assess the association of household SHS exposure and mortality risk. Hazard ratios (HRs) and 95\% confidence intervals (CIs) were estimated. Follow-up began at the time of interview and ended on the date of death or December 31, 2011, whichever came first. We then used multivariate models to adjust for potential confounders. Model 1 included age, gender, race, education level, family income, urbanization classification of the county, medication, and NHANES III phase. Model 2 included variables in model 1, self-reported general health status, and comorbidities (hypertension, diabetes, hypercholesterolemia, myocardial infarction, chronic kidney disease, COPD/ emphysema). Model 3 included variables in model 2, physical functioning, heart rate, systolic, and diastolic blood pressure. However, analysis of Model 3 was exploratory because physical functioning, blood pressure, and heart rate are probably in the causal pathway between SHS exposure and mortality among patients with heart failure. Subgroup analyses were performed among ex-smokers (those who had smoked at least 100 cigarettes) and never-smokers (those who hadn't smoked 100 cigarettes). A sensitivity analysis was performed by excluding those who died within 6 months. We imputed missing values of covariates using multiple imputation with a Markov Chain Monte Carlo method. Variables listed in Table 1 were included in the imputation model. The assumption of proportional hazards was confirmed for all variables.

All $P$ values are two-tailed, and estimates with $P$ values of less than 0.05 were considered statistically significant. All analyses were performed using STATA 13.

\section{Results}

Baseline characteristics

Baseline characteristics were summarized in Table 1 . Eighty-eight patients were exposed to household SHS, and 484 were not. Exposed patients were younger than the unexposed. Patients with household SHS exposure were more likely to be non-Hispanic Black, have a family income of more than 20,000 dollars, and have a larger household size, while those without exposure were more likely to live in an urbanized area, take beta-blockers, and have a history of myocardial infarction. The mean diastolic blood pressure in exposed group was $3.5 \mathrm{mmHg}$ higher than that in unexposed group. Other baseline characteristics were comparable in both groups.

\section{All-cause mortality}

During a mean follow-up period of 9.2 years, there were 475 deaths (72 deaths in exposed group and 403 deaths in unexposed group). Rates of death per person-year were comparable between two groups (88.0 and 90.4 deaths per 1000 person-years in exposed group and unexposed group, respectively) (Table 2). Kaplan-Meier survival curves showed similar results ( $\mathrm{P}$ for log-rank 
Table 1 Baseline characteristics of included participants

\begin{tabular}{|c|c|c|c|}
\hline & Exposed & Unexposed & $\mathrm{p}$ \\
\hline$n$ & 88 & 484 & \\
\hline Male, \% & 47.3 & 47.7 & 0.943 \\
\hline Age, years & $66.1+17.1$ & $70.8+12.6$ & 0.001 \\
\hline Race, \% & & & 0.003 \\
\hline Non-Hispanic White & 37.5 & 49.4 & \\
\hline Non-Hispanic Black & 31.8 & 16.3 & \\
\hline Mexican-American & 25.0 & 31.2 & \\
\hline Other & 5.7 & 3.1 & \\
\hline Region, \% & & & 0.162 \\
\hline Northeast & 12.5 & 12.4 & \\
\hline Midwest & 14.8 & 17.6 & \\
\hline South & 59.1 & 47.5 & \\
\hline West & 13.6 & 22.5 & \\
\hline Urbanization Classificationª $\%$ & & & 0.002 \\
\hline 1 & 55.7 & 61.8 & \\
\hline 0 & 44.3 & 38.2 & \\
\hline Education level, \% & & & 0.759 \\
\hline Education $<12 y$ & 65.5 & 67.2 & \\
\hline Education $\geq 12 y$ & 34.5 & 32.8 & \\
\hline \multicolumn{4}{|l|}{ Economic Status, \% } \\
\hline Poverty income ratio $<2$ & 64.5 & 68.2 & 0.509 \\
\hline Poverty income ratio $\geq 2$ & 35.5 & 31.8 & \\
\hline Family income $<20,000$ dollars & 60.4 & 73 & 0.019 \\
\hline Family income $\geq 20,000$ dollars & 39.6 & 27 & \\
\hline Military service, $\%$ & 18.2 & 18.5 & 0.941 \\
\hline \multicolumn{4}{|l|}{ Household Size, \% } \\
\hline 1 person & 0 & $124(25.6)$ & $<0.001$ \\
\hline 2 persons & $26(29.6)$ & $223(46.1)$ & \\
\hline$\geq 3$ persons & $62(70.5)$ & $137(28.3)$ & \\
\hline \multicolumn{4}{|l|}{ Medication, \% } \\
\hline ACEI & $17(19.3)$ & $105(21.7)$ & 0.617 \\
\hline$\beta$-Blocker & $6(6.82)$ & $79(16.32)$ & 0.021 \\
\hline Diuretic & $30(34.1)$ & $216(44.6)$ & 0.066 \\
\hline Digitalis & $25(29.4)$ & $144(29.6)$ & 0.799 \\
\hline Ex-smoker, \% & 51.0 & 46.6 & 0.443 \\
\hline \multicolumn{4}{|l|}{ Comorbidities, \% } \\
\hline Hypertension $^{\mathrm{b}}$ & 75.0 & 74.6 & 0.935 \\
\hline Diabetes $^{c}$ & 33.0 & 35.1 & 0.694 \\
\hline Hypercholesterolemia $^{d}$ & 71.6 & 70.3 & 0.819 \\
\hline COPD/emphysema ${ }^{e}$ & 22.7 & 30.2 & 0.157 \\
\hline Chronic kidney disease $^{f}$ & 71.5 & 76.8 & 0.309 \\
\hline History of myocardial infarction & 39.8 & 52.2 & 0.033 \\
\hline Self-reported general health status, \% & & & 0.535 \\
\hline
\end{tabular}


Table 1 Baseline characteristics of included participants (Continued)

\begin{tabular}{|c|c|c|c|}
\hline & Exposed & Unexposed & $p$ \\
\hline Good or fair & 68.8 & 72.1 & \\
\hline Hospitalization during last year & 43.2 & 38.9 & 0.445 \\
\hline See doctors $>5$ times during last year & 45.4 & 51.4 & 0.311 \\
\hline $\begin{array}{l}\text { Physical functioning: } \\
\text { Difficulty in walking } 10 \text { steps without rest, \% }\end{array}$ & & & 0.148 \\
\hline Yes & 62.7 & 53.5 & \\
\hline No & 37.3 & 46.5 & \\
\hline Systolic blood pressure, mmHg & $142.2+24.1$ & $141.7+23.7$ & 0.849 \\
\hline Diastolic blood pressure, mmHg & $77.3+14.3$ & $73.8+13.5$ & 0.028 \\
\hline Heart rate, bpm & $74.4+12.3$ & $72.6+12.9$ & 0.234 \\
\hline NHANES III phase, \% & & & 0.314 \\
\hline 1988-1991 & $54(61.4)$ & $269(55.6)$ & \\
\hline 1991-1994 & $34(38.6)$ & $215(44.4)$ & \\
\hline Mean follow-up, years & $9.3 \pm 7.1$ & $9.2 \pm 6.9$ & 0.920 \\
\hline
\end{tabular}

${ }^{a}$ : Central or fringe counties of metro areas with a population of more than 1 million; 0 : All other areas

${ }^{b} \mathrm{BP} \geq 140 / 90 \mathrm{mmHg}$ or on antihypertensive medications or self-report

${ }^{c} \mathrm{HbA}_{1 \mathrm{c}} \geq 6.5 \%$ or on diabetes medications or self-report

${ }^{\mathrm{d}}$ Total serum cholesterol $\geq 240 \mathrm{mg} / \mathrm{dL}$ or on anti-cholesterol medications or self-report

${ }^{e}$ Forced expiratory volume $1 /$ forced vital capacity ratio $<0.7$ or self-report

fUrine albumin to urine creatinine ratio $>30 \mathrm{mg} / \mathrm{g}$ or estimated glomerular filtration rate $<60 \mathrm{~mL} / \mathrm{min} / 1.73 \mathrm{~m}^{2}$

test $=0.864)$ (Fig. 1). Results of Cox regression models were summarized in Table 3. In the univariate analysis, household SHS exposure was not associated an increased mortality risk (HR: $0.98,95 \%$ CI: $0.76-1.26, p=$ 0.854). However, after adjusting for demographic variables, socioeconomic variables, and medication in Model 1, household SHS exposure was associated of a $43 \%$ increase of mortality risk (HR: $1.43,95 \%$ CI: $1.10-1.86$, $p=0.007$ ). Model 2 further adjusted for self-reported general health status and baseline comorbidities, and HR for the association was 1.47 (95\% CI: 1.13-1.92, $p=$ 0.005). Result in Model 3 was consistent. In subgroup analyses, the associations of household SHS and mortality risk did not differ significantly between ex-smokers and never-smokers ( $\mathrm{p}$ for interaction $>0.1$ ). Excluding death within 6 months did not significantly change the results (HR: $1.38,95 \%$ CI: $1.05-1.82, p=0.020$ for Model 1; HR: 1.42 , 95\% CI: $1.08-1.88, p=0.014$ for Model 2; HR: $1.35,95 \%$ CI: $1.02-1.80, p=0.037)$.

\section{Discussion}

This study suggested that household SHS exposure was associated with an increased risk of death among heart failure patients. The results were consistent in analyses with different levels of adjustment. As far as we know, this is the first study to assess the association between household SHS exposure and mortality risk of heart failure.

Suskin et al. analyzed data from the Studies of Left Ventricular Dysfunction trials, and found that active smoking was associated with a $41 \%$ increase of mortality risk among patients with left ventricular dysfunction. This study also found no significant difference in mortality risks between ex-smokers and never-smokers, suggesting that smoking cessation could reduce the mortality risk [9]. In our analyses among currently nonsmoking adults, HRs for associations of household SHS exposure and mortality risk ranged from 1.40 to 1.47 with different levels of adjustment. In the subgroup analyses, associations of household SHS and mortality risk were similar among ex-smokers and never-smokers. These results implied that effect of household SHS on mortality risk could be as large as active smoking, and that exposure to household SHS could eliminate the benefit of smoking cessation among patients with heart failure. The substantial effect of household SHS on heart failure prognosis makes it an unignorable risk factor. More attention should be paid on avoiding exposure of

Table 2 Mortality incidence rate in household secondhand smoke exposed and unexposed group

\begin{tabular}{llll}
\hline & Number of mortality & Person-year & Incidence rate, per 1000 person-year \\
\hline Exposed & 72 & 817.8 & 88.0 \\
Unexposed & 403 & $4,48.8$ & 90.4 \\
\hline
\end{tabular}




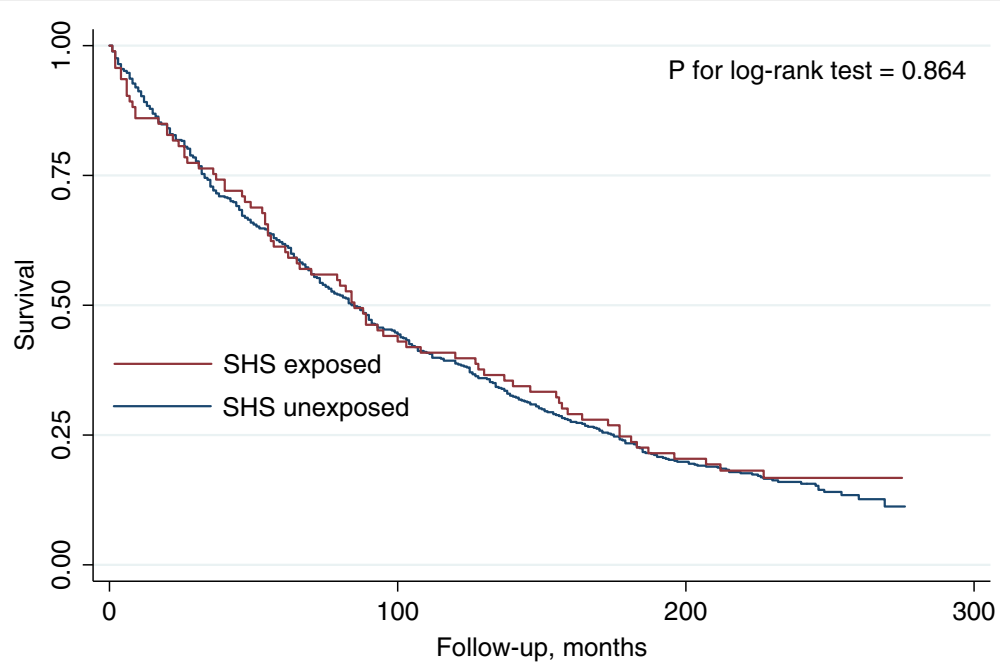

Fig. 1 Kaplan-Meier survival curves of household secondhand smoke exposed and unexposedgroup.

household SHS in management of heart failure. Personal smoking cessation will be in vain if a smoke-free environment is not provided.

Unlike multivariate analyses, univariate analyses did not found any significant associations. This could be explained by differences of baseline characteristics, especially age. Among the heart failure patients included in our analyses, those exposed to household SHS were significantly younger, probably reflecting shorter life spans of patients in this group. Harmful effect of household SHS could be covered by survival advantage of younger age. Besides, relatively high family income might also contribute to the differences between univariate and multivariate analyses [15].

The mechanisms of this detrimental effect are still not clear, but there are several possible explanations. Studies have shown that both acute and chronic SHS exposure are associated with decreased heart rate variability, which indicates a shift in the sympathovagal balance toward sympathetic predominance [16-18]. Sustained activation of sympathetic nervous system exerts deleterious effects on cardiovascular system in heart failure patients [19]. SHS exposure also leads to increased inflammation and oxidative stress, which are important in the progression of heart failure [11, 20, 21].

Our study has several limitations. First, history of heart failure was obtained from answer to questionnaire instead of medical record, which could introduce significant recall bias. Second, we lacked information about etiology of heart failure, New York Heart Association class, and ejection fraction, and could not include them in the multivariate analysis. These are important factors that affect the prognosis of heart failure. Third, only a very low proportion of patients in this study took medication for heart failure. Therefore, results of this study needed to be verified in current standard heart failure cohort. Fourth, we did not assess SHS exposure in the workplace, public places, social situations, etc. SHS exposure outside of the household could bias the results. Fifth, the sample size was limited. There were only 88 participants in the exposed group, which might explain the non-significant results in subgroup analyses. Given

Table 3 Associations of household SHS exposure and mortality risk among currently nonsmoking patients with heart failure

\begin{tabular}{|c|c|c|c|c|c|c|c|c|c|c|c|c|c|c|c|c|}
\hline & \multicolumn{4}{|c|}{ Univariate Model } & \multicolumn{4}{|c|}{ Model 1} & \multicolumn{4}{|c|}{ Model 2} & \multicolumn{4}{|c|}{ Model 3} \\
\hline & $\mathrm{HR}$ & $95 \% \mathrm{Cl}$ & $\mathrm{p}$ & $\begin{array}{l}\text { p for } \\
\text { interaction }\end{array}$ & $\mathrm{HR}$ & $95 \% \mathrm{Cl}$ & $\mathrm{p}$ & $\begin{array}{l}\text { p for } \\
\text { interaction }\end{array}$ & $H R$ & $95 \% \mathrm{Cl}$ & $\mathrm{p}$ & $\begin{array}{l}\text { p for } \\
\text { interaction }\end{array}$ & $\mathrm{HR}$ & $95 \% \mathrm{Cl}$ & $\mathrm{p}$ & $\begin{array}{l}p \text { for } \\
\text { interaction }\end{array}$ \\
\hline Overall & 0.98 & $\begin{array}{l}0.76- \\
1.26\end{array}$ & 0.864 & & 1.43 & $\begin{array}{l}1.10- \\
1.86\end{array}$ & 0.007 & & 1.47 & $\begin{array}{l}1.13- \\
1.92\end{array}$ & 0.005 & & 1.40 & $\begin{array}{l}1.07- \\
1.84\end{array}$ & 0.016 & \\
\hline $\begin{array}{l}\text { Never- } \\
\text { smoker }\end{array}$ & 1.02 & $\begin{array}{l}0.72- \\
1.46\end{array}$ & 0.889 & 0.307 & 1.41 & $\begin{array}{l}0.96- \\
2.08\end{array}$ & 0.079 & 0.639 & 1.51 & $\begin{array}{l}1.02- \\
2.23\end{array}$ & 0.040 & 0.921 & 1.39 & $\begin{array}{l}0.93- \\
2.09\end{array}$ & 0.112 & 0.620 \\
\hline $\begin{array}{l}\text { Ex- } \\
\text { smoker }\end{array}$ & 0.96 & $\begin{array}{l}0.67- \\
1.37\end{array}$ & 0.829 & & 1.48 & $\begin{array}{l}1.02- \\
2.17\end{array}$ & 0.040 & & 1.46 & $\begin{array}{l}0.98- \\
2.18\end{array}$ & 0.066 & & 1.47 & $\begin{array}{l}0.98- \\
2.22\end{array}$ & 0.065 & \\
\hline
\end{tabular}

HR hazard ratio, $\mathrm{Cl}$ confidence interval

Model 1 adjusted for age, gender, race, education level, family income, urbanization classification, and medications, NHANES III phase

Model 2 adjusted for variables in Model 1, general health status, and comorbidities

Model 3 adjusted for variables in Model 2 and physical functioning, heart rate, systolic, and diastolic blood pressure 
the limitations mentioned above, results of this study should be interpreted with caution. Sixth, reverse causality could not be ruled out in this study. As family member might pay more attention to patient care if heart failure was more severe. Therefore, advanced heart failure patients might be less likely exposed to household SHS, and the effect of SHS in this study might be underestimated. Seventh, SHS was not included as a timedependent variable. As SHS exposure status could change during follow-up, using baseline SHS could introduce bias. Eighth, our study assessed SHS only as a binary variable. The dose-response relation of SHS and prognosis of heart failure should be evaluated in detail in future study.

Nevertheless, there were also several strengths in this study. First, using data from a nation-wide survey, the studied participants were representative of heart failure patients in community. Second, current smokers were not included in this study to avoid the influence of active smoking. Although former smokers were included, the effect of former smoking was also evaluated in a subgroup analysis. Third, average follow-up period was almost 10 years in this study, which was long enough to assess the long-term effect of SHS.

\section{Conclusions}

In conclusion, household SHS exposure was associated with increased mortality risk in currently nonsmoking patients with heart failure, which was similar in magnitude to the effect of active smoking. The detrimental effect of household SHS exposure was consistent among ex-smokers never-smokers. Avoidance of household SHS should be a crucial part of management of heart failure.

\section{Abbreviations \\ Cl: Confidence interval; HR: Hazard ratio; NHANES: National Health and nutrition examination surveys; SHS: Secondhand smoke}

\section{Acknowledgments}

We thanked Zexuan Wu for her advice in manuscript writing.

\begin{abstract}
Authors' contributions
$\mathrm{CL}$ and YD developed the idea of the study. XH obtained the data, performed analysis, interpreted the results, and wrote the manuscript. JZ participated in data analysis and results interpretation. $\mathrm{JH}$ participated in manuscript writing and revision. All authors have read and approved the manuscript and agreed with their contributions.
\end{abstract}

\section{Funding}

This work was supported by Natural Science Foundation of China (No. 81770392, No. 81770394, No. 81700344 , No. 81800344 , No. 81800345), Science and Technology Program Foundation of Guangdong (No. 2017A020215156) and Medical Research Foundation of Guangdong Province (No. 2017A030310311, No. A2018107, No. A2018082).

\section{Availability of data and materials}

Data used in this study were available on the website of National Center for Health Statistics, https://www.cdc.gov/nchs/tutorials/NHANES/Preparing/
Download/Frame2_III.htm. The NHANES III database was open to the public and did not require any ethical or administrative permission.

\section{Ethics approval and consent to participate}

An ethics statement was not required for this work. Data used in the analysis were anonymized. The NHANES III database was open to the public and did not require any ethical or administrative permission.

\section{Consent for publication}

Not Applicable.

\section{Competing interests}

The authors declared no conflict of interest.

\section{Author details}

'Department of Cardiology, The First Affiliated Hospital of Sun Yat-sen University, Guangzhou, China. ${ }^{2} \mathrm{NHC}$ Key Laboratory of Assisted Circulation, Sun Yat-sen University, Guangzhou, China.

Received: 1 January 2019 Accepted: 19 November 2019

Published online: 02 December 2019

References

1. Bleumink GS, Knetsch AM, Sturkenboom MC, Straus SM, Hofman A, Deckers JW, Witteman JC, Stricker BH. Quantifying the heart failure epidemic: prevalence, incidence rate, lifetime risk and prognosis of heart failure the Rotterdam study. Eur Heart J. 2004;25:1614-9.

2. Ceia F, Fonseca C, Mota T, Morais H, Matias F, de Sousa A, Oliveira A. Prevalence of chronic heart failure in southwestern Europe: the EPICA study. Eur J Heart Fail. 2002;4:531-9.

3. Mosterd A, Hoes AW. Clinical epidemiology of heart failure. Heart. 2007;93: 1137-46.

4. Redfield MM, Jacobsen SJ, Burnett JJ, Mahoney DW, Bailey KR, Rodeheffer RJ. Burden of systolic and diastolic ventricular dysfunction in the community: appreciating the scope of the heart failure epidemic. JAMA. 2003:289:194-202.

5. Djousse L, Driver JA, Gaziano JM. Relation between modifiable lifestyle factors and lifetime risk of heart failure. JAMA. 2009:302:394-400.

6. Levy D, Kenchaiah S, Larson MG, Benjamin EJ, Kupka MJ, Ho KK, Murabito $J M$, Vasan RS. Long-term trends in the incidence of and survival with heart failure. N Engl J Med. 2002;347:1397-402.

7. Roger VL, Weston SA, Redfield MM, Hellermann-Homan JP, Killian J, Yawn BP, Jacobsen SJ. Trends in heart failure incidence and survival in a community-based population. JAMA. 2004;292:344-50.

8. Ponikowski P, Voors AA, Anker SD, Bueno H, Cleland JG, Coats AJ, Falk V, Gonzalez-Juanatey JR, Harjola VP, Jankowska EA, Jessup M, Linde C, Nihoyannopoulos P, Parissis JT, Pieske B, Riley JP, Rosano GM, Ruilope LM, Ruschitzka F, Rutten FH, van der Meer P. ESC guidelines for the diagnosis and treatment of acute and chronic heart failure: the task force for the diagnosis and treatment of acute and chronic heart failure of the European Society of Cardiology (ESC). Developed with the special contribution of the heart failure association (HFA) of the ESC. Eur J Heart Fail. 2016;18:891-975.

9. Suskin N, Sheth T, Negassa A, Yusuf S. Relationship of current and past smoking to mortality and morbidity in patients with left ventricular dysfunction. J Am Coll Cardiol. 2001;37:1677-82.

10. Yancy CW, Jessup M, Bozkurt B, Butler J, Casey DJ, Drazner MH, Fonarow GC, Geraci SA, Horwich T, Januzzi JL, Johnson MR, Kasper EK, Levy WC, Masoudi FA, McBride PE, McMurray JJ, Mitchell JE, Peterson PN, Riegel B, Sam F, Stevenson LW, Tang WH, Tsai EJ, Wilkoff BL. 2013 ACCF/AHA guideline for the management of heart failure: a report of the American College of Cardiology Foundation/American Heart Association task force on practice guidelines. J Am Coll Cardiol. 2013;62:e147-239.

11. Barnoya J, Glantz SA. Cardiovascular effects of secondhand smoke: nearly as large as smoking. Circulation. 2005;111:2684-98.

12. Weeks SG, Glantz SA, De Marco T, Rosen AB, Fleischmann KE. Secondhand smoke exposure and quality of life in patients with heart failure. Arch Intern Med. 2011:171:1887-93.

13. National Center For Health Statistics. National Health and Nutrition Examination Survey: Questionnaires, datasets, and related documentation. Available from https:/www.cdc.gov/nchs/nhanes/nhanes_questionnaires.htm. 
14. National Center For Health Statistics. NCHS 2011 Linked Mortality Files Matching Methodology. Available from https://www.cdc.gov/nchs/data/ datalinkage/2011_linked_mortality_file_matching_methodology.pdf.

15. Verma AK, Schulte PJ, Bittner V, Keteyian SJ, Fleg JL, Pina IL, Swank AM, FitzGerald M, Ellis SJ, Kraus WE, Whellan DJ, O'Connor CM, Mentz RJ. Socioeconomic and partner status in chronic heart failure: relationship to exercise capacity, quality of life, and clinical outcomes. Am Heart J. 2017;183:54-61.

16. Dinas $P C$, Koutedakis $Y$, Flouris AD. Effects of active and passive tobacco cigarette smoking on heart rate variability. Int J Cardiol. 2013;163:109-15.

17. Felber DD, Schwartz J, Schindler C, Gaspoz JM, Barthelemy JC, Tschopp JM, Roche F, von Eckardstein A, Brandli O, Leuenberger P, Gold DR, AckermannLiebrich $U$. Effects of passive smoking on heart rate variability, heart rate and blood pressure: an observational study. Int J Epidemiol. 2007;36:834-40

18. Pope CR, Eatough DJ, Gold DR, Pang Y, Nielsen KR, Nath P, Verrier RL, Kanner RE. Acute exposure to environmental tobacco smoke and heart rate variability. Environ Health Perspect. 2001;109:711-6.

19. Lymperopoulos A, Rengo G, Koch WJ. Adrenergic nervous system in heart failure: pathophysiology and therapy. Circ Res. 2013;113:739-53.

20. Anker SD, von Haehling S. Inflammatory mediators in chronic heart failure: an overview. Heart. 2004;90:464-70.

21. Munzel T, Gori T, Keaney JJ, Maack C, Daiber A. Pathophysiological role of oxidative stress in systolic and diastolic heart failure and its therapeutic implications. Eur Heart J. 2015;36:2555-64.

\section{Publisher's Note}

Springer Nature remains neutral with regard to jurisdictional claims in published maps and institutional affiliations.

Ready to submit your research? Choose BMC and benefit from:

- fast, convenient online submission

- thorough peer review by experienced researchers in your field

- rapid publication on acceptance

- support for research data, including large and complex data types

- gold Open Access which fosters wider collaboration and increased citations

- maximum visibility for your research: over $100 \mathrm{M}$ website views per year

At $\mathrm{BMC}$, research is always in progress.

Learn more biomedcentral.com/submissions 